\title{
THE RESULTS OF PANTALAR REDUCTION IN THE MANAGEMENT OF CONGENITAL TALIPES EQUINOVARUS
}

\author{
N. N. GHALI, R. B. SMITh, A. D. CLAYDEN, F. F. SILK
}

From the General Infirmary, Leeds

\begin{abstract}
One hundred and twenty-five patients with 194 feet affected by congenital talipes equinovarus were treated by the senior author during the period 1959 to 1980 . Of these, 70 patients presented either at birth or in the early neonatal period, and 55 were seen later, having been referred from other centres. Seventy-five patients were subsequently reviewed by two of us; the remaining $\mathbf{5 0}$ were assessed from records and research files. Patients seen within four weeks of birth were termed "early", the remainder "late".

Of the early group of 70 patients, 44 (with 68 affected feet) were reviewed and 26 (with 41 affected feet) were assessed from records. Excellent or good results were achieved in 94 per cent of feet treated conservatively and in 82 per cent of feet which required pantalar release. Of the 55 late referrals 32 patients (with 55 affected feet) were reviewed and 23 (with 30 affected feet) were assessed from records. Satisfactory results were slightly less frequent, but were achieved in 75 per cent of cases.

There was no statistical correlation between early soft-tissue release and a good final outcome, but there was a positive statistical correlation between good clinical results and a high talocalcaneal index. Osseous correction (a laterally based wedge tarsectomy or a triple arthrodesis) was necessary at a later date in four feet (four per cent) of those who presented early and in 13 feet (15 per cent) of late referrals.
\end{abstract}

Assessment of the treatment of congenital talipes equinovarus is beset with problems. Until the last 20 years expectations were low. Elaborate methods of stretching, manipulating, plastering and splinting were designed to coax a series of soft-tissue structures joined together with an inelastic tether into a plantigrade platform. This often produced damage to the delicate cartilaginous anlage of the tarsal bones, or caused a break in the midtarsal region (rocker-bottom foot). The spurious correction so produced caused abnormal growth and the need for later operations on bone (Dwyer 1959; Evans 1961).

The vogue for earlier and more extensive surgical release seemed to herald an improvement (Main et al. 1977), but the follow-up of their patients was relatively short. Enthusiasm is often damped when late results are reviewed. Wynne-Davies (1964) had found a high proportion of patients with residual hindfoot deformity in a series managed by a variety of methods; similarly, Reimann and Becker-Anderson (1974) had reported a 50 per cent relapse rate in those treated by early posterior

N. N. Ghali, FRCS, Senior Orthopaedic Registrar

F. F. Silk, MCh, FRCS, Consultant Orthopaedic Surgeon

The General Infirmary, Great George Street, Leeds LS1 3EX, England.

R. B. Smith, FRCS, Consultant Orthopaedic Surgeon

Royal Preston Infirmary, Sharoe Green Lane North, Fulwood, Preston, England.

A. D. Clayden, BSc, PhD, Senior Lecturer in Medical Statistics

University of Leeds, Leeds LS2 9JT, England.

Requests for reprints should be sent to Mr F. F. Silk.

(C) 1983 British Editorial Society of Bone and Joint Surgery 0301-620X/83/1016-0001 \$2.00

VOL. 65-B. No. I, JANUARY 1983 release, and Somppi and Sulamaa (1971) had found a 23 per cent recurrence rate after limited posterior release.

Only when a large series of patients, all treated along similar lines, is studied over a considerable period of time can valid inferences be drawn as to the efficacy of treatment. The object of this present paper is to report such a series, with emphasis on an extended "pantalar release" for severe and resistant deformities.

\section{CONSERVATIVE TREATMENT}

The late J. M. P. Clark, writing in collaboration with the senior author (Clark and Silk 1976) described a programme of treatment which has been in use at the General Infirmary, Leeds, since 1959. An early report on the results has been presented (Clark 1968). Stretching and splinting forms the basis of early management, using the method described by Holland (1956).

Treatment should begin as soon after birth as possible; the sole exception is the premature infant needing an incubator, in whom the risk of producing pressure sores by early splinting outweighs the loss of early correction inherent in delay.

It is a hallmark of the method that correction is attempted in two separate stages rather than trying to correct all components of the deformity simultaneously. Single-stage correction puts the inextensible and already tight tibialis posterior under extreme tension which may break the foot at the tarsometatarsal junction and crush the cartilaginous models of the tarsal bones.

Stage I. Inversion of the heel, adduction of the forefoot 


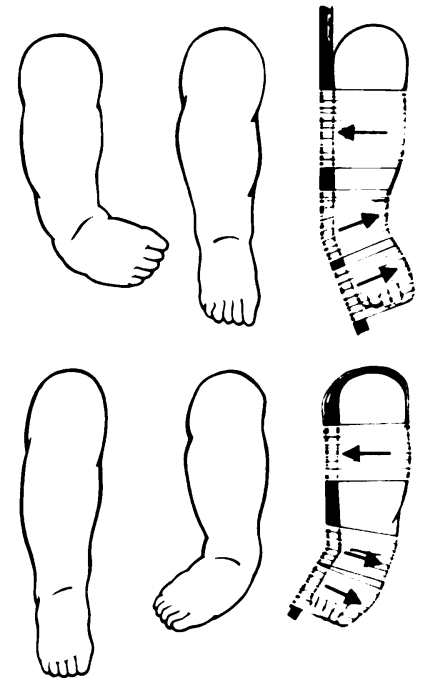

Fig. 1

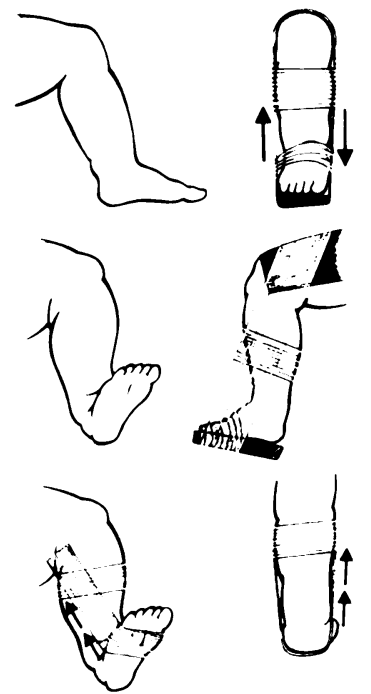

Fig. 2
Stretching and strapping. Figure $1-$ Stage $I$. The top row shows the uncorrected deformity and the first application of the splint. The second row shows the correction obtained and the final position of the splint. Figure 2-Stage II. Top row: the equinus foot with its sole piece in position is manipulated as shown by the arrows. The remaining drawings show the correction aimed at and the strapping which maintains it (in the bottom row the sole piece has been omitted for clarity).

and supination of the forefoot are corrected by a series of manipulations every two or three days carried out without anaesthesia; after each manipulation a malleable splint is applied to the lateral aspect from below the knee to the toes (Fig. 1). No attempt is made to correct the equinus component at this stage.

Stage II. Assuming that by four or five weeks of age the inversion, adduction and supination have been corrected, an attempt is now made to correct equinus by manipulation. A padded aluminium splint is then applied to the sole of the foot and is strapped in place, maintaining the foot in dorsiflexion and eversion. The procedure is repeated every three days (Fig. 2). The fact that the splint has a rigid platform prevents the foot from breaking across the tarsometatarsal region and also protects the metatarsal heads from being crushed.

If conservative treatment is proving inadequate and operation needed, this is usually apparent within eight weeks, and often earlier in resistant cases.

\section{OPERATIVE TREATMENT}

Indications. There are but three: an apparently small heel (in reality a high heel), inability to evert and dorsiflex the foot to a right angle, and incompetence of the medial ray.

Incompetence is revealed by a persisting transverse crease over the navicular and by a positive telescoping test. The integrity of the medial ray, which consists of the talus, navicular, medial cuneiform, first metatarsal and phalanges, depends on the normal alignment at each articulation. In congenital talipes equinovarus the navicular articulates with the medial aspect of the talar neck; thus the medial ray is broken at the midtarsal level and unless the navicular is reduced fully and squarely onto the talar head, incompetence of the medial ray persists. The application of longitudinal pressure to the first metatarsal causes the ray to move into varus, breaking the talonavicular joint and so accentuating the crease overlying the navicular; this is known as the telescoping test.

These clinical observations can be reinforced by standard radiographs which, if closed treatment has failed, demonstrate persisting lack of the normal divergence of the talus in relation to the calcaneum ("closed scissors of the hind foot") and adduction of the forefoot; these indicate failure to deal with the essential dislocations (Fig. 3).
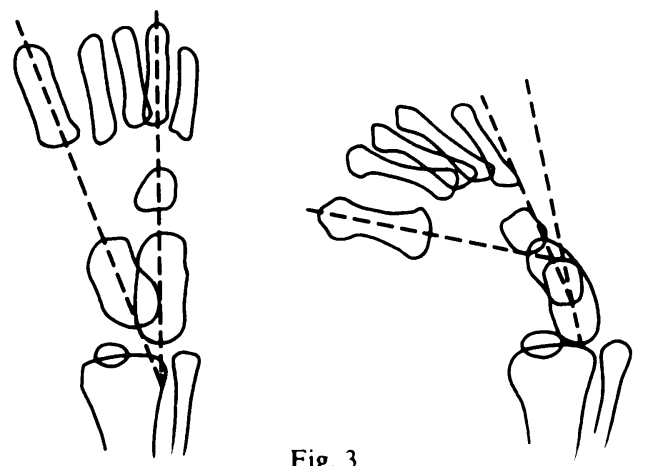

Fig. 3

Drawings to show the talocalcaneal angle in a normal foot (left) and in a foot with talipes equinovarus (right). Reproduced from Tether, contracture and deformity (Clark and Silk 1976).

Technique. In essence the operation is an extensive release of all the structures contributing to the deformity. This requires extensive division of the capsules of the tarsal and midtarsal joints. The talocalcaneal interosseous ligaments and the lateral portion of the calcaneocuboid ligament alone are regarded as sacrosanct. The flexor digitorum longus is used as a motor to replace the inextensible tibialis posterior.

The technique has been described in detail elsewhere (Clark and Silk 1976). It is strongly recommended that this account be consulted before the operation is attempted for the first time; the authors believe that the quality of the result can be adversely affected by failure to observe any one of a number of small points of technique.

The operation falls naturally into a series of 12 steps. Step 1: the skin incision is extensive, reaching from the neck of the first metatarsal to the mid-calf; the skin flaps are reflected from the deep fascia to maximise their viability. Step 2: the posterior tibial nerve is dissected to the point where it divides into medial and lateral plantar nerves, so that the viability of the intrinsic muscles will not be compromised when they are stripped off the tarsal bones. The long plantar ligament is divided in front of the calcaneal tuberosity. Steps 3 and 4: the tendon of tibialis posterior is identified; traction demonstrates its inextensibility. The tendon of flexor digitorum longus, a 
muscle which rarely shares the inextensibility, is developed into the sole and severed at the point where it divides into four terminal slips. The distal part of the sheath can be dissected leaving a small pulley at the malleolus, but the tendon should not be avulsed from the sheath. Tibialis posterior is divided high in the calf and the tendon withdrawn from its retinacular tunnel. Step 5: the talonavicular joint is widely opened; the distal part of the tibialis posterior can be used as a guide to the plane of cleavage between the talus and navicular, which otherwise can be difficult to see. Step 6: the talocalcaneal joints are likewise widely opened. Step $7:$ all the capsular structures of the calcaneocuboid joint, other than the lateral capsule, must be divided before reduction is possible; the lateral capsule is retained as the locating hinge against which reduction is held. Step 8 : the medial, anterior and posterior aspects of the capsule of the ankle joint are released and also the capsule of the posterior talocalcaneal joint. The lateral ligament is divided back to the lateral malleolus. The interosseous ligament is retained. Step 9: the lateral capsule of the talocalcaneal joint is divided with scissors which are passed over the neck and head of the talus. This is regarded as a crucial step and differs from the procedure described by other authors; not until these fibres have been divided will the talocalcaneal dislocation reduce and allow the radiological "scissors" to open fully. Step 10: the calcaneal tendon is lengthened in $\mathrm{Z}$ fashion. Step 11: the tendon of flexor digitorum is attached to the stump of the tibialis posterior tendon, the suture line being distal in the foot. Step 12: the skin is closed without tension. The limb is held in a padded L-shaped splint, but no attempt is made to maintain full correction until the skin is healed at two weeks. Thereafter full correction is maintained in a long leg plaster cast for three months.

\section{CLINICAL MATERIAL}

One hundred and twenty-five patients with 194 affected feet have been treated for congenital talipes equinovarus by one of us (FFS) over the last 21 years. Ninety-four patients were male and 31 female; 56 patients had unilateral and 69 had bilateral deformities though these were not necessarily symmetrical in severity. The family history was negative for first-degree relatives in 108 patients and positive in 17.

Those children referred within the first four weeks of life were regarded as "early presentations" and are considered as a distinct group whose management followed a uniform plan. The remaining group of "late presenters" includes patients whose age at presentation and whose previous treatment varied widely (see Table I). No child with less than three years follow-up was included in this series. The age at follow-up is shown in Figure 4 ; the median and mean are both 11.6 years.

All infants presenting under the age of three months received conservative treatment in the first instance. The previous treatment of late referrals is shown in Table II.
Table I. Age of presentation of the 125 patients

\begin{tabular}{|llcc|}
\hline Group & Age & $\begin{array}{l}\text { Number of } \\
\text { patients }\end{array}$ & $\begin{array}{l}\text { Number of } \\
\text { feet }\end{array}$ \\
\hline Early presentation & 0-4 weeks & 70 & 109 \\
Late presentation & $4-12$ weeks & 8 & 12 \\
& 3-6 months & 2 & 4 \\
& 6-9 months & 2 & 2 \\
& 9-12 months & 3 & 6 \\
& 1-2 years & 11 & 15 \\
& 2-3 years & 5 & 8 \\
& 3-6 years & 19 & 29 \\
6-9 years & 4 & 7 \\
TOTAL & Over 12 years & 1 & 2 \\
& & 125 & 194 \\
\hline
\end{tabular}

Table II. Previous treatment of late referrals

\begin{tabular}{|lll|}
\hline Previous treatment & Number of patients & Number of feet \\
\hline Conservative & 29 & 45 \\
Operative & 20 & 31 \\
None & 6 & 9 \\
TOTAL & 55 & 85 \\
\hline
\end{tabular}

Conservative treatment consisted of stretching, strapping, Denis Browne boots, manipulation under anaesthesia or serial plasters. Operative treatment of this group included tenotomy of the calcaneal tendon, posterior release, posteromedial release and osteotomy of the calcaneum.

\section{METHODS OF ASSESSMENT}

Seventy-five patients with 113 affected feet were independently reviewed at a special clinic by two of us (NNG, RBS) and fully assessed clinically and radiologically. The scoring system is based on that described by Wynne-Davies (1964) with the addition of two points for radiographic angles (Table III).

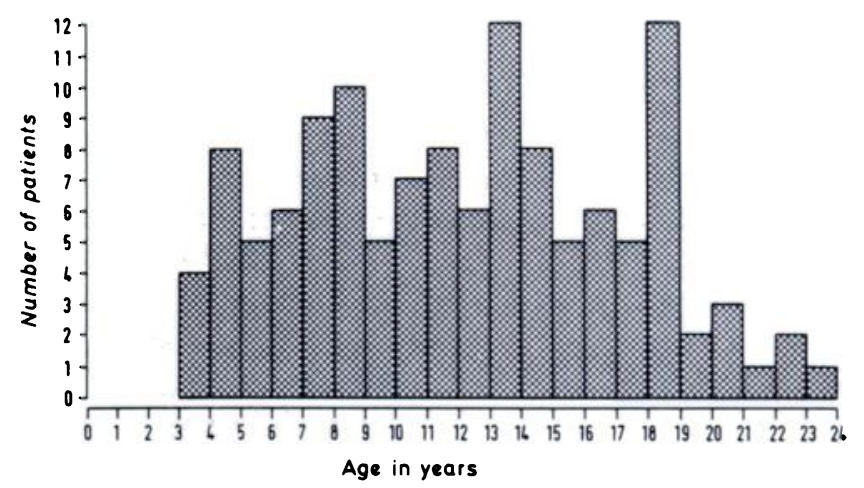

Fig. 4

Histogram showing the ages of the patients at the time of follow-up. 
Clinical assessment. A record was made of function, sporting activities, type of work, symptoms, shape of foot, residual deformity and pressure areas, range of movements of the ankle, subtalar and midtarsal joints, size of calf, leg length and discrepancy of shoe sizes.

Radiological assessment. The method described by Beatson and Pearson (1966) was used. Standard radiographs are taken with the foot plantarflexed 30 degrees in a special plastic splint. In the anteroposterior view lines are drawn through the talus parallel to its medial border, and through the calcaneum parallel to its lateral border. In the lateral view lines are drawn through the central axis of the talus, and parallel to the lower border of the calcaneum. The two angles are added and the sum is termed the talocalcaneal index (see Figs 11 to 13).

Patients assessed from records. In addition to the 75 patients who came up for review, there were a further 50 (with 81 affected feet) many of whom have left Leeds and who failed to attend. However, detailed assessment according to the same criteria was possible as a research file had been kept on all patients with club feet. Additional information was obtained from a questionnaire in 11 patients. The results in the patients assessed from records are presented separately, but it is clear that they differ little from those in patients who came for review.

All results were classified as excellent, good or poor

Table III. Numerical analysis of results (maximum 14 points)

\begin{tabular}{|c|c|c|}
\hline \multirow[t]{5}{*}{ FUNCTION } & Maximum 4 points & Normal \\
\hline & Subtract 1 point & $\begin{array}{l}\text { Mild decrease in } \\
\text { performance }\end{array}$ \\
\hline & Subtract 2 points & $\begin{array}{l}\text { Moderate performance, } \\
\text { impaired activities, pain }\end{array}$ \\
\hline & Subtract 3 points & $\begin{array}{l}\text { Inability to participate in } \\
\text { heavy work or sport }\end{array}$ \\
\hline & Subtract 4 points & $\begin{array}{l}\text { Difficulty in walking and } \\
\text { persistent pain }\end{array}$ \\
\hline \multirow[t]{2}{*}{ APPEARANCE } & Maximum 4 points & Normal \\
\hline & Subtract 1 point & $\begin{array}{l}\text { Each for: varus heel or } \\
\text { forefoot, equinus, coronal } \\
\text { or sagittal breach, callosi- } \\
\text { ties and planovalgus } \\
\text { (overcorrection) }\end{array}$ \\
\hline \multirow[t]{3}{*}{ MOVEMENTS } & Maximum 4 points & Fully mobile \\
\hline & Subtract 1 point & $\begin{array}{l}\text { Each for: mild restriction } \\
\text { of ankle or subtalar } \\
\text { movements }\end{array}$ \\
\hline & Subtract 2 points & $\begin{array}{l}\text { Each for: severe restric- } \\
\text { tion of ankle or subtalar } \\
\text { movements }\end{array}$ \\
\hline \multirow[t]{3}{*}{ RADIOGRAPHS } & Maximum 2 points & $\begin{array}{l}\text { Talocalcaneal index over } \\
40 \text { degrees }\end{array}$ \\
\hline & 1 point & $\begin{array}{l}\text { Talocalcaneal index } 20-40 \\
\text { degrees }\end{array}$ \\
\hline & No points & $\begin{array}{l}\text { Talocalcaneal index less } \\
\text { than } 20 \text { degrees }\end{array}$ \\
\hline
\end{tabular}

(Main et al. 1977); the numbers of each are given and compared with the numerical grading.

\section{RESULTS}

Early presentations. Of 70 patients with 109 affected feet, 32 patients with 52 feet were treated by non-operative methods and 38 patients with 57 feet required open reduction. Of these 70 patients, 44 with 68 feet were reviewed (Table IV) and 26 with 41 feet were assessed

Table IV. Results in patients presenting early and who were seen at review (68 affected feet)

\begin{tabular}{|llll|}
\hline $\begin{array}{l}\text { Method of } \\
\text { treatment }\end{array}$ & Points & Number of feet & Percentage \\
\hline Conservative & $10-14$ & 30 & 94 \\
& $<9$ & 2 & 6 \\
Operative & $10-14$ & 30 & 83 \\
& $<9$ & 6 & 17 \\
\hline
\end{tabular}

Table V. Results in patients presenting early and who were assessed from the records (4l affected feet)

\begin{tabular}{|llll|}
\hline $\begin{array}{l}\text { Method of } \\
\text { treatment }\end{array}$ & Grading & Number of feet & Percentage \\
\hline Conservative & Excellent and good & 19 & 95 \\
& Poor & 1 & 5 \\
Operative & Excellent and good & 18 & 86 \\
& Poor & 3 & 14 \\
\hline
\end{tabular}

Table VI. Results in patients who presented later and who were seen at review (55 affected feet)

\begin{tabular}{|llll|}
\hline $\begin{array}{l}\text { Method of } \\
\text { treatment }\end{array}$ & Points & Number of feet & Percentage \\
\hline Conservative & $10-14$ & 10 & 59 \\
& $<9$ & 7 & 41 \\
Operative & $10-14$ & 31 & 82 \\
& $<9$ & 7 & 18 \\
TOTAL & Excellent and good & 41 & 75 \\
& Poor & 14 & 25 \\
\hline
\end{tabular}

Table VII. Results in patients who presented later and who were assessed from the records ( 30 affected feet)

\begin{tabular}{|llll|}
\hline $\begin{array}{l}\text { Method of } \\
\text { treatment }\end{array}$ & Grading & Number of feet & Percentage \\
\hline Conservative & Excellent and good & 4 & 67 \\
& Poor & 2 & 33 \\
Operative & Excellent and good & 19 & 79 \\
& Poor & 5 & 21 \\
TOTAL & Excellent and good & 23 & 77 \\
& Poor & 7 & 23 \\
\hline
\end{tabular}


from records (Table $\mathrm{V}$ ). Thus in patients presenting in the first four weeks of life, the outcome was satisfactory in 94 per cent of feet treated conservatively and in 84 per cent of feet treated operatively (Figs 5 to 13).

Among the patients who presented early, all the poor results were in those initially classified as having severe deformities (though not all those initially graded as severe ended up with low scores). These poor results were in feet which were resistant to conservative treatment and which came to operation at between 3 and 18 months. In four cases the soft-tissue release had to be repeated and in two of these wedge tarsectomy was later performed. Later presentations. Fifty-five patients with 85 affected feet were referred after the age of one month; their age at presentation is shown in Table I. Of these, 32 patients with 55 affected feet were reviewed and 23 patients with 30 affected feet were assessed from records.

Those presenting before the age of four years with sufficient severity were subjected to soft-tissue correction and those presenting later to osseous correction. Patients who were referred relatively early with mild deformity were treated conservatively. Table VI shows that in 75

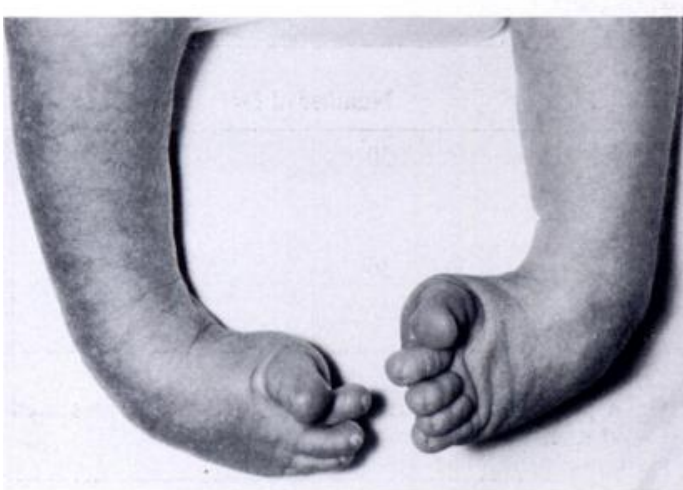

Fig. 5

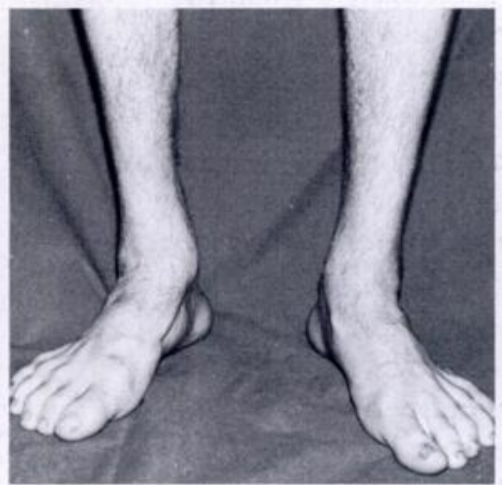

Fig. 6

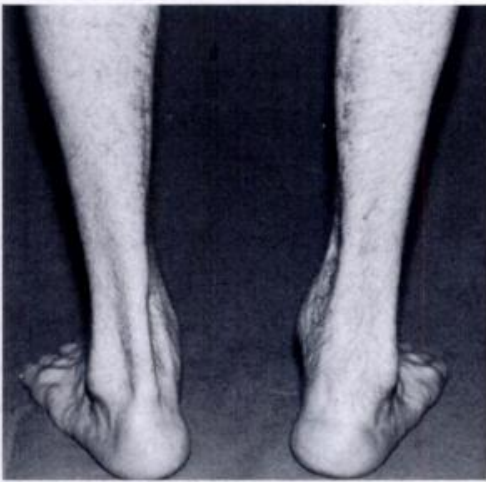

Fig. 7

Figure 5-The appearance, soon after birth, of a boy with bilateral talipes; pantalar reduction was performed bilaterally at the age of one year, but the right side needed revision when he was aged 3 years and 10 months. Figures 6 and $7-$ The appearance at the age of 17

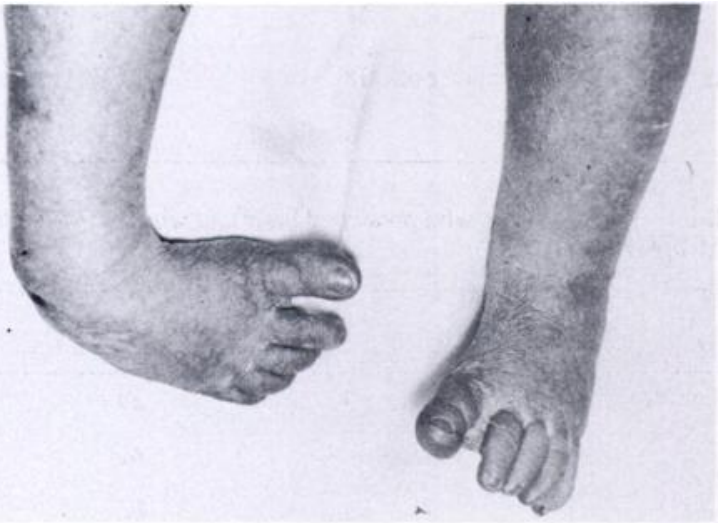

Fig. 8

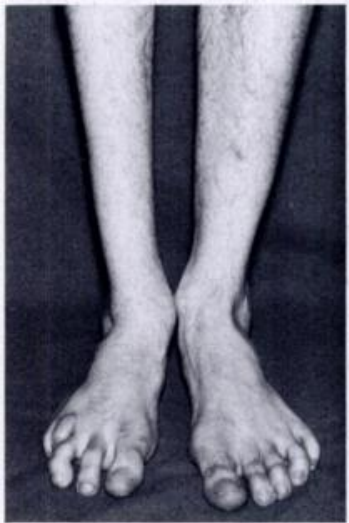

Fig. 9

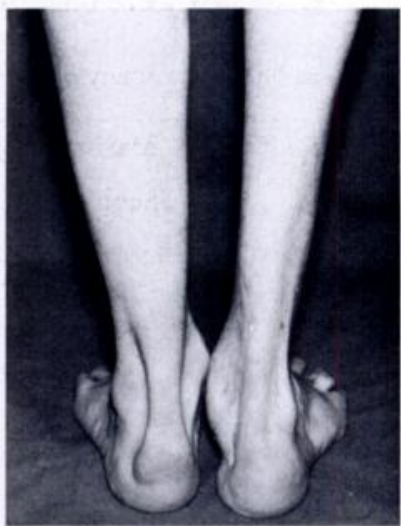

Fig. 10

Figure 8-Unilateral talipes soon after birth. Operation was performed at the age of three years. Figures 9 and 10-The appearance at the age of 24 years.

Standard anteroposterior and lateral views of the patient in Figures 8, 9 and 10

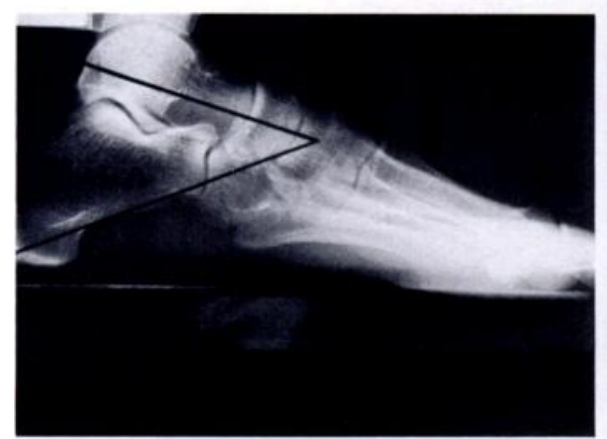

Fig. 11

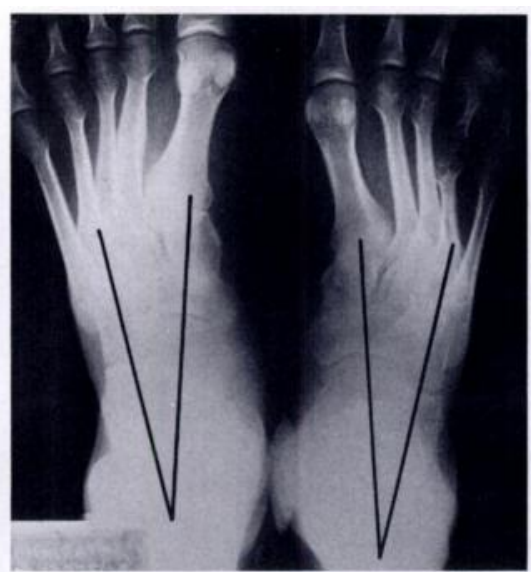

Fig. 12
The talocalcaneal angle of the previously deformed right foot is now almost normal.

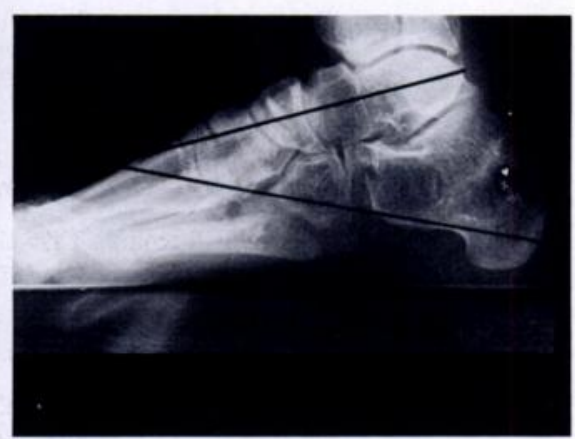

Fig. 13 
per cent of patients reviewed the outcome was satisfactory, and Table VII illustrates that the results in those assessed from records were very similar.

Measurements. Children with bilateral club feet all showed more wasting of the calf (measured midway between the tibial tubercle and the medial malleolus) on the more severely affected side. In unilateral cases, even those with an excellent result showed relative wasting compared with the normal leg. The affected leg was usually one to two centimetres shorter than the normal leg. The greatest discrepancy was four centimetres in a patient with a poor result on one side and an excellent result on the other.

In unilateral cases and in patients with asymmetrical bilateral deformity the feet differed in size; in 90 per cent of such patients the affected foot was one to one-and-ahalf U.K. shoe sizes smaller than its fellow.

All 75 patients (with 113 affected feet) who attended for review were subjected to radiography in standard positions. Table VIII shows that the talocalcaneal index derived from these films correlates well with the clinical results. Table IX shows the comparison of numerical with clinical assessment.

Operative complications. Four patients suffered superficial wound infection; in one Clostridium welchii was isolated, but without evidence of gas gangrene. These four all required revision of the soft-tissue release and later osseous correction; all were classified as poor. This complication is of great consequence and can only be avoided by scrupulous care in handling the skin edges and by waiting two weeks after operation before manipulating the foot to achieve final correction.

Overcorrection, leading to excessive valgus, was noted in 14 feet. Their distribution and results are shown in Table X, and an example is shown in Figures 14 and 15. A mild valgus appearance is compatible with a good or excellent result. Those with a poor result in the late presentation group had often undergone osseous correction in addition to soft-tissue release (Figs 14 and 15).

Timing of operation. We originally felt that the timing of the pantalar release might influence the outcome but, as Table XI demonstrates, we found no significant statistical

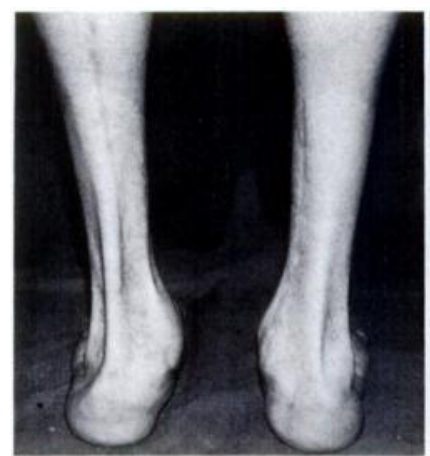

Fig. 14

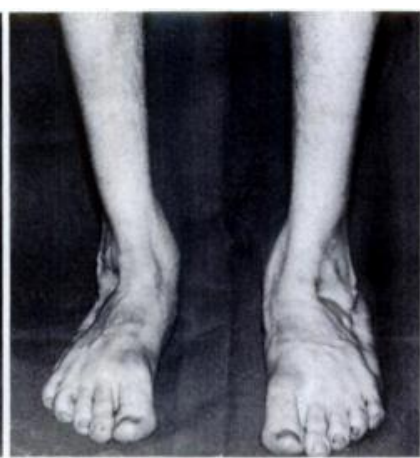

Fig. 15
This patient, aged 18 , shows overcorrection of both feet, more marked on the left.
Table VIII. Correlation of radiological measurements with clinical findings at follow-up (early and late referrals combined)

\begin{tabular}{|lllc|}
\hline & \multicolumn{2}{l}{ Number of feet with } & \\
\cline { 2 - 3 } Talocalcaneal index & $\mathbf{1 0 - 1 4}$ points & $<9$ points & Total \\
\hline $0-10$ & 0 & 2 & 2 \\
$11-20$ & 0 & 0 & 0 \\
$21-25$ & 1 & 4 & 5 \\
$26-30$ & 5 & 1 & 6 \\
$31-35$ & 4 & 4 & 8 \\
$36-40$ & 19 & 0 & 19 \\
$41-45$ & 20 & 3 & 23 \\
$46-50$ & 14 & 2 & 16 \\
$51-55$ & 13 & 0 & 13 \\
$56-60$ & 14 & 0 & 14 \\
$61-65$ & 5 & 0 & 5 \\
$66-70$ & 2 & 0 & 2 \\
TOTAL & 97 & 16 & 113 \\
\hline
\end{tabular}

Mann Witney U Test $=4.2(P<0.001)$

Table IX. Comparison of numerical with clinical assessment in the series reviewed including early and late presentations

\begin{tabular}{|llcc|}
\hline & \multicolumn{3}{l}{ Number of feet } \\
\cline { 2 - 4 } Points scored & Excellent & Good & Poor \\
\hline $13-14$ & 55 & 4 & 0 \\
$11-12$ & 7 & 16 & 1 \\
$9-10$ & 0 & 6 & 3 \\
$<8$ & 0 & 2 & 19 \\
TOTAL & 62 & 28 & 23 \\
\hline
\end{tabular}

Table X. Feet which ended up with excessive valgus

\begin{tabular}{|llll|}
\hline & \multicolumn{2}{l}{ Results } & \\
\cline { 2 - 4 } Presentation & Excellent & Good & Poor \\
\hline Early & 1 & 1 & 2 \\
Late & 0 & 2 & 8 \\
\hline
\end{tabular}

Table XI. The timing of operation and its effect on the result

\begin{tabular}{|lcccc|}
\hline Time & Excellent & Good & Poor & Total \\
\hline 0-3 months & 3 & 2 & 0 & 5 \\
3-6 months & 6 & 8 & 4 & 18 \\
6-12 months & 10 & 8 & 5 & 23 \\
1-3 years & 18 & 11 & 6 & 35 \\
Over 3 years & 12 & 12 & 14 & 38 \\
Number of observations & 49 & 41 & 29 & 119 \\
\hline
\end{tabular}

Kruskall Wallis analysis of variance $(H=2.65$; not significant) 
relationship between early operation and a good final result. It may well be that severe deformity prompts the surgeon into early operation, but we have not found that operating within the first few months of life produces a better clinical result.

\section{DISCUSSION}

Most authors who have dissected club feet describe the essential abnormality as a dislocation of the navicular and forefoot to the medial side of the talar neck; the calcaneum rotates to lie beneath the talar head, thereby moving into equinus and producing the "small" heel (Adams 1866; Brockman 1930; Irani and Sherman 1963). It is this displacement which our treatment aims to correct by what we have termed "pantalar" reduction and the objective is to achieve this without disturbing growth of the tarsal bones.

Over the 21 years that this review covers, attempts have been made to provide a consistent plan of treatment supervised by one surgeon (FFS) who has, in every case, performed the operation or assisted at it. Manipulation and strapping has produced consistently good results in mild and in moderately severe cases and the technique has undergone little modification. Operation has been needed for severe cases and its timing has usually been dictated by the severity of the deformity. At the eightweek stage it is apparent in the most severe cases that operation is required, but in the less severe cases conservative treatment has sometimes been continued for longer before deciding to operate. We did not find that delay adversely affected the eventual outcome; this contrasts with the findings of Main et al. (1977) who stated that the earlier the operation the better the result.

Patients who needed only conservative treatment did very well, as might be expected. Those referred in the first four weeks of life and severe enough to need open reduction produced satisfactory results in 84 per cent which compares favourably with previously reported series (Wynne-Davies 1964; Attenborough 1966; Main et al. 1977). In patients referred later pantalar release still produced reasonable results ( 82 per cent satisfactory) up to three or four years of age, though, as compared with the early group, more needed subsequent bony correction. Of those presenting late, in all 75 per cent were satisfactory; this included the results of both conservative and operative treatment.

Radiological examination proved valuable for two reasons. First, because radiographs taken at three months show clearly the abnormal position of the hindfoot with a narrow talocalcaneal angle; this information, added to clinical evidence of a resistant deformity, gives strong support for early surgical release. Secondly, because there is a strong association between the talocalcaneal index and the clinical result.

We should like to thank William Heinemann, London, for permission to reproduce a résumé of the operative steps and one diagram from the book by the late J. M. P. Clark, Tether, Contracture and Deformity. Dr W. D. A. Smith and Dr D. W. Clark anaesthetised the patients, and their skill and co-operation were indispensable. We should also like to thank Mr Arthur Naylor, FRCS, and Mr M. J. Abberton, FRCS, for their critical appraisal, the Department of Medical Illustration and Photography at the University of Leeds for the art work, and Mrs Eunice Schober for preparation of the manuscript.

\section{REFERENCES}

Adams W. Club foot. Its causes, pathology and treatment. London: J \& A Churchill, 1866.

Attenborough CG. Severe congenital talipes equinovarus. J Bone Joint Surg [Br] 1966; 48-B:31-9.

Beatson TR, Pearson JR. A method of assessing correction in club feet. J Bone Joint Surg [Br] 1966;48-B:40-50.

Brockman EP. Congenital club foot (talipes equinovarus). Bristol: John Wright, 1930.

Clark JMP. Early detection and management of the unreduced club foot. Proc R Soc Med 1968;61:779-82.

Clark JMP, Silk FF. Congenital talipes. In: Clark JMP. Tether, contracture and deformity. London: William Heinemann Medical Books Ltd, 1976:119-55.

Dwyer FC. Osteotomy of the calcaneum for pes cavus. J Bone Joint Surg [Br] 1959;41-B:80-6.

Evans D. Relapsed club foot: operative technique and results in 30 feet. J Bone Joint Surg [Br] 1961;43-B:722-33.

Holland KL. The physiotherapeutic treatment of some congenital club foot deformities. Physiotherapy 1956;42:206-10.

Irani RN, Sherman MS. Pathological anatomy of club foot. J Bone Joint Surg [ Am] 1963;45-A :45-52.

Main BJ, Crider RJ, Polk M, Lloyd-Roberts GC, Swann M, Kamdar BA. The results of early operation in talipes equino-varus. A preliminary report. J Bone Joint Surg [Br] 1977; 59-B:337-41.

Reimann I, Becker-Anderson H. Early surgical treatment of congenital club foot. Clin Orthop 1974;102:200-6.

Somppi E, Sulamaa M. Early operative treatment of congenital club foot. Acta Orthop Scand 1971;42:513-20.

Wynne-Davies R. Talipes equinovarus. J Bone Joint Surg [Br] 1964;46-B:464-76. 